\title{
Perspectives on Nursing Policy
}

Michael Villeneuve RN, MSc

Scholar-in-Residence, Canadian Nurses Association

Editor, Canadian Journal of Nursing Leadership

When she took over the helm as its new editor-in-chief, Lynn Nagle commented that the Canadian Journal of Nursing Leadership could function as one vehicle "to facilitate and support the dialogues that can drive strategy and policy development." " To help bring that goal to life, I am honoured to join Lynn, my co-editors Greta Cummings and Patricia Petryshen and the talented Longwoods team in the role of editor for the journal's policy and innovation pillar of work.

Like Lynn, my career and thinking have been profoundly influenced by the journal's previous editor-in-chief, Dot Pringle. By a happy coincidence of history, Dot began her term as dean of nursing at the University of Toronto at the same time that I slid into graduate school in 1988. As anyone who knows her will understand, I quickly figured out that I had moved into the big league and that I better "up my game." I have benefited from her interest and support throughout my career - and she has never failed to provide sage advice with a twist of good humour any time I asked for it.

In that moment of time I lucked out in many more ways. Kay Arpin was leading the theory aspects of the master's program at that time, and she changed the whole way I thought about the discipline of nursing. Kay and Dot co-led a marvelous "trends and issues" course that introduced the whole mysterious world of public policy. And among a long roster of great teachers in that remarkable time were Ellen Hodnett and Judith Shamian, Dorothy Wylie (who I often joke was teaching the original Dorothy M. Wylie Nursing Leadership Institute as the faculty's nursing administration course) and Raisa Deber, who titillated our minds with her insightful, sometimes wry perspectives on public policy.

It was a vibrant time of change and transformation in my life and at the Faculty of Nursing. And now, more than 20 years later, I find myself in another place of transition as Lynn takes on the role of editor-in-chief, and we take the journal in new directions that will build on the strong base created by Dot, Dorothy Wylie and Jan Dick. 
I have reflected many times on Pierre Trudeau's comment that "Luck is the time when preparation and opportunity meet." That kind of "luck" has served me well throughout my career, which has hardly been a planned trajectory. I find myself in 2010 feeling lucky again. I hope I have the preparation needed to meet the opportunity being offered by Lynn, and by Anton and Dianne at Longwoods. I am grateful and excited to be part of the team.

\section{A Decade of Policy Leadership}

Over the coming year we will feature a special series, $A$ Decade of Policy Leadership, in which we will introduce journal readers to some of the roles taken on by nurse leaders in the public policy realm, with an eye to understanding their achievements. And without dwelling on the negative, we also want to learn what has not worked - or where structures were created that perhaps gave visibility to nurses while effectively keeping them out of the loop of real policy influence.

Nineteenth-century librettist William S. Gilbert once remarked that "it isn't so much what's on the table that matters as what's on the chairs." With that in mind, I want to feature stories of these policy roles, but importantly, to infuse them with commentary and reflections from some of the nurse leaders who have filled them. The first issue will focus on policy roles at the provincial/territorial level. Across the year we will look at similar roles at national and then international levels. Finally, in the fourth

\section{Introducing the Editorial Team}

We are extremely pleased to introduce the esteemed trio of professionals who are our new editors. First, Michael Villeneuve, will be editor for health policy and Innovation. His perspectives are drawn from his years in practice, research and health policy. Most recently, he has worked as a senior nursing consultant in the Office of Nursing Policy, Health Canada, and since 2006 has served as scholar-in-residence with the Canadian Nurses Association. Mike maintains special interests in nursing leadership, futures thinking, health human resources, human/civil rights, equity and diversity.

Our editor for research is Dr. Greta Cummings from the University of Alberta, a highly regarded scholar with a research program focused on leadership science in health services. Dr. Cummings's career has included roles as a senior administrative leader in hospital, regional and provincial health services. She has systematically documented the effects, both positive and negative, of specific leadership practices on outcomes for the health system, for the healthcare workforce and for patients.

Last but not least, as editor for practice, Dr. Patricia Petryshen brings to the journal senior executive leadership experience in large, complex health systems and in government. Patricia has held academic appointments at several universities, conducted research related to the outcomes of patient care and published widely. She has chaired and been a member of many national and provincial councils, boards and foundations.

Our new team's collective depth and breadth of experience in nursing and healthcare is sure to enrich the journal's editorial excellence. From myself, Longwoods, our readers and contributors, a warm welcome to each of you. In addition to vetting manuscript submissions and identifying potential reviewers, each of them will be contributing a column in at least one issue of the journal over the course of the year. This article is the first...

Lynn Nagle, RN, PhD

Editor-in-Chief 
issue of the series, we will analyze what we learned from the findings of the previous three issues, and identify the structures, roles and policy levers that worked (or didn't) to have a lasting influence on healthy public policy.

In this endeavour I am pleased to have the assistance and always insightful thinking of my colleague and friend, Kathleen MacMillan, who is presently dean of health sciences at Humber College in Toronto. Kathleen recently has undertaken her own reflection on her time as Ontario's first chief nursing officer. She will work with me to shape the special series focusing on nursing policy leadership, and I know journal readers will benefit from her broad thinking and her honest, sometimes mischievous, spirit.

\section{Policy and Innovation}

The whole area of influencing policy and bringing innovations to life in the journal will, of course, take a great deal more effort than the series of papers I have talked about here. The achievements of nurses in shaping broader public policy issues often are poorly understood, and they merit a great deal more analysis, marketing and celebration. In this regard I want to solicit your help by inviting those of you who are in these kinds of roles to record the outcomes of your work and submit them for publication in the journal. I join Lynn in encouraging papers from Canadian nurses as well as international colleagues; there have been tremendous nurse-led policy successes in other countries, and we all have much to learn from one another.

The related domain of "innovation" in nursing remains a concern to me. The word has enjoyed a resurgence of popularity among nurses, policy leaders and governments over the past decade. But what we haven't done very well is actually innovate in many meaningful ways within the discipline or practice of nursing. In fact, when I had a conversation in 2007 with Dr. Joyce Fitzpatrick ${ }^{2}$ about my concerns around the discipline of nursing, she felt the worry was well founded, saying there really has not been much ground-breaking work published in this area for the past 20 years. Given the tremendous pace of change in society, a whole revolution in micro-technology and the ongoing (sometimes desperate) need for improved access to healthcare services, how can it be that the underpinnings of nursing and its practice have stood nearly still through all that?

Hands-on hospital nursing certainly has changed to incorporate and reflect new technologies. But as someone who has been a patient over the past year, in both Canadian and American hospital settings, for far too many days than I care to remember, I can say that other than different kinds of pumps and technical procedures I did not see evidence of nursing that was much different from the way I first practised it at the beside nearly 30 years ago. Certainly there was little 
evidence of any more critical thinking or different levels of decision-making than in the early 1980s despite being surrounded by the most educated generation of registered nurses in history. Practical nursing, on the other hand, has vastly expanded its scope and approach in hospitals and communities, as has medicine, which is much more patient-focused and flexible than a generation ago. What has happened to registered nursing in this time?

Where there is evidence of innovation in nursing, it often has remained locked in boutique kinds of models where it "shines" in one or two settings and rarely moves much beyond that. Quite apart from not transferring well across employment settings, my observations of my own care and those of family members confirm the presence of an issue that vexed us 30 years ago: innovation sometimes does not even translate down a single hospital corridor to the next unit within a single employment setting.

Why have we not been able to crack this problem? Is it a quirk of human nature that we share with every other profession and workplace, or is there something here unique to nursing? Are we completely vulnerable to the personalities that lead and make up teams, even on a shift-by-shift basis?

Again, I want to invite you, our readers, to submit papers that describe innovations in nursing practice, leadership, education and science - especially those where outcomes have been measured and replicated. But more than that, I want to encourage you to reflect on the kinds of challenges I have talked about here. I know you will not all agree with my observations. Perhaps we can use the journal as a place for commentary and debate beyond its very useful role as a place to share descriptions of innovative practices. Personally, I feel that if this journal does not at least occasionally arouse some discomfort or disagreement, then we will have failed in our leadership mission. Too much comfort and agreement makes me worry. The journal should not be a place that simply doles out handy policy and innovation bites and is then forgotten. Rather, it should be a place of engagement for current and emerging nurse leaders to think, debate, contribute, sometimes disagree, and I hope, to imagine.

I am genuinely pleased to be part of the fourth generation of leadership of CJNL, and I hope you will want to join in the journey forward.

\section{Notes}

1 Nagle, L. 2010. “Taking Over the Helm.” Canadian Journal of Nursing Leadership 23(1): 1-2.

2 Joyce Fitzpatrick, Elizabeth Brooks Ford Professor of Nursing and former dean (1982-1997), Frances Payne Bolton School of Nursing, Case Western Reserve University, Cleveland, Ohio (personal communication). 